\title{
TITLE IX AND THE SPATIAL CONTENT OF FEMALE EMPLOYMENT—OUT OF THE LAB AND INTO THE LABOR MARKET
}

\author{
Michael Baker \\ Kirsten Cornelson \\ Working Paper 22641 \\ http://www.nber.org/papers/w22641 \\ NATIONAL BUREAU OF ECONOMIC RESEARCH \\ 1050 Massachusetts Avenue \\ Cambridge, MA 02138 \\ September 2016
}

Baker gratefully acknowledges the research support of a Canada Research Chair at the University of Toronto. We thank Jessica Burley and Rebecca Clark for excellent research assistance and Diane Halpern and Gary Solon for helpful comments. The views expressed herein are those of the authors and do not necessarily reflect the views of the National Bureau of Economic Research.

NBER working papers are circulated for discussion and comment purposes. They have not been peer-reviewed or been subject to the review by the NBER Board of Directors that accompanies official NBER publications.

(C) 2016 by Michael Baker and Kirsten Cornelson. All rights reserved. Short sections of text, not to exceed two paragraphs, may be quoted without explicit permission provided that full credit, including $(\odot)$ notice, is given to the source. 
Title IX and the Spatial Content of Female Employment—Out of the Lab and into the Labor Market

Michael Baker and Kirsten Cornelson

NBER Working Paper No. 22641

September 2016

JEL No. I28,J16,J24

\section{ABSTRACT}

Sports participation is a leading environmental explanation of the male advantage in some spatial skills. We exploit the large increase in females' high school sports participation due to Title IX to test this hypothesis. We relate Title IX induced increases in females' sport participation to the spatial content of their occupational employment as captured by Dictionary of Occupational Titles codes, and a test of three dimensional spatial rotation. We find little evidence that this increase in sports participation had an impact on either of these measures.

Michael Baker

Department of Economics

University of Toronto

150 St. George Street

Toronto, ON M5S 3G7

CANADA

and NBER

baker@chass.utoronto.ca

Kirsten Cornelson

Department of Economics

University of Toronto

150 St. George Street

Toronto, ON M5S 3G7

CANADA

kirsten.cornelson@utoronto.ca 


\section{Introduction}

“Lab research” on sex differences in humans finds that females and males differ in some (but not all) spatial skills. On balance this sex difference favors males. "Why?" is an important question for our knowledge of how skills are formed, but also for understanding persistent female/male differences in field of study and occupational choice. Spatial skills are strong predictors of entry into STEM fields (e.g., Sorby 2009, Wai et al. 2009) and so this sex difference might help account for the lower presence of females in these occupations. ${ }^{1}$ Baker and Cornelson (2016) report that spatial skills and depth perception, as captured by the Dictionary of Occupational Titles (DOT), are statistically and economically significant predictors of gender separation in the labor market. Based on a simulation, they conclude that negating this selection on spatial skills would, all else equal, lower the Duncan Index ${ }^{2}$ of gender segregation in the labor market by roughly 10 percent in both 1970 and 2012. ${ }^{3}$

The sex difference in some dimensions of spatial cognition emerges at very young ages (e.g., Moore and Johnson 2008, Quinn and Liben 2008). In tables 1 and 2 we report sex differences in tests of two dimensional and three dimensional spatial rotation by grade (controlling for age) and by age (controlling for grade), from the Project Talent

${ }^{1}$ Spatial visualization skill training is part of the NSF funded ENGAGE program intended to "Retain undergraduates, particularly underrepresented groups, [in engineering] by improving their day-to-day classroom and educational experiences”. http://www.engageengineering.org

2 The Duncan Index is a common measure of segregation. It is often interpreted as indicating (in this application) the percentage of females (or males) who would need to change occupations if the occupational distribution of men and women were to be the same.

${ }^{3}$ While eliminating selection on spatial skills would reduce the amount of employment segregation, the authors show that it would also tend to increase the male-female wage gap, because it would reduce female employment in a number of highly-paid occupations that have low spatial aptitude ratings. 
data. ${ }^{4}$ This is a survey of roughly 5 percent of the US high school population in 1960. The test scores are standardized so the estimated sex differences are in standard deviations. The results indicate that a) the sex difference in spatial abilities captured by these tests is evident by high school entry, and b) the sex difference grows over the high school years. They point to an origin of these sex differences at younger ages and suggest that the differences are potentially affected by the passage through high school.

There are at least three contending hypotheses of why gender differences in spatial skills exist. One is based on the effects of the higher androgen exposure males experience in the pre and post natal periods. A second is based in the principle of evolutionary selection and females' historical role as gatherers and males' historical role as hunters. A third, and the focus here, is based in corresponding sex differences in environmental stimuli that differentially promote the development of spatial skills in males and females.

As researchers have pointed out, unlike for quantitative, verbal and reasoning skills, spatial skill development is not an element of normal school curricula (e.g., Halpern et al. 2007). Therefore, non- or extra-curricular activities have emerged as potentially important early life environmental factors affecting spatial skill development (Sherman 1967). Most recently, boys higher use of computers and greater gaming activities have been investigated as agents of spatial cognition (e.g., Cherney and London 2006, Cherney 2008, Connelly et al. 2012). However for a majority of current labor market participants a more historically relevant environmental factor may be males’

\footnotetext{
4 The Project Talent data are from a roughly 5 percent survey of high school students in 1960. Two dimensional spatial rotation is evaluated by a 24 item test, while three dimensional spatial rotation is evaluated on a 16 item test.
} 
higher rates of participation in sports and physical play (e.g., Baenninger and Newcombe 1989, Bjorkland and Brown 1989, Halpern 2012).

As has been noted previously, the relationship between males' higher participation in sports and better spatial skills in some dimensions needn't be causal. Boys may simply participate more in sports because they have higher spatial skills for some other reason (Crawford and Chaffin 1997, Halpern 2012).

Environmental theories of sex differences in skills and attributes are commonly evaluated indirectly by the age at which the difference first appears. The reasoning is, the younger the age of emergence a sex difference the less likely environmental factors can be important. This testing strategy therefore typically aims to rule out the entire class of environmental explanations rather than distinguish among its competing elements. While perhaps sound in principle, this approach faces the challenge that it is difficult to test very young children and the results of tests at young ages are often open to interpretation. ${ }^{5}$

While the sex differences in spatial skills have been tracked to young ages (e.g., table 1), so have sex typed sports participation and play. We adopt a different empirical strategy examining the impact of a large, quasi experimental change in females' sports participation at childhood ages-Title IX. As documented by Stevenson $(2007,2010)$ Title IX, which banned sex discrimination in programs and activities at federally funded educational institutions, led to a dramatic increase in female participation in high school level sports over the 1970s. Female participation rose from under 5 percent at the start of the decade to close to 30 percent by the end. At the same time male participation

${ }^{5}$ See, for example, Connellan et al.'s (2000) evidence of females' people orientation and males' mechanical/things orientation in a sample of one day old babies, and the resulting debate (e.g., Halpern 2012). 
remained fairly constant at between 50 and 60 percent. Stevenson reports that this increase in participation led to consequent increases in females' education attainment, labor force participation and, intriguingly, their choices of occupations. We follow up on this latter finding to discover if there was a corresponding change in the spatial content of women's jobs.

We measure the spatial content of employment using the Dictionary of Occupational Titles (DOT). The DOT codes provide ratings of occupations in terms of a variety of aptitudes, skills, physical demands, environments and cognitive requirements. We use the aptitude "spatial” and the physical demand "depth perception" to capture the spatial content employment.

A direct method of evaluating the impact of sports participation on spatial cognition is with measures of individuals' spatial skills. Unfortunately tests of spatial skills are not regularly conducted on national samples. That said, we do have access to national level tests that broadly bracket the enactment of Title IX, and also bring this evidence to the analysis.

We begin by briefly reviewing the literature on sex differences in spatial skills and providing an overview of Title IX. After outlining our measurement and empirical strategy, we present OLS and IV results of the impact of sports participation on the spatial content of women's jobs. The estimates are consistently very small, negative and statistically insignificant. We then show that this evidence is consistent with estimates of the impact of Title IX induced sports participation on direct measures of the spatial skills of high school seniors.

In a series of robustness checks we show that our results are not a result of cross 
state differences in pre-existing trends in the spatial content of employment, and that they are robust to an alternative estimation procedure that uses comparisons of spatial employment changes between men and women within the same state. We also explore the possibility that the results are a result of differences in the spatial content of the particular sports that men and women play, and show that any such differences are unlikely to be leading to our results. The bulk of women's increased participation was in sports that rely relatively heavily on spatial skills (such as basketball and tennis). Weighting increases in participation based on an external ranking of sports' spatial demand makes no difference to our results.

Finally, we show that our results are unlikely to be explained by changes in the overall educational, physical and interpersonal demands of jobs chosen by women (which might mask an increase in spatial aptitude if they are negatively correlated with spatial skills across jobs.) We perform a principal components analysis of these broader job characteristics, and show that none of the components that capture the spatial skills are significantly affected by Title IX. On net, it seems that the increase in sports participation that we analyze had very little influence on the types of jobs chosen by women.

Our results contribute to a small but growing literature in economics on the sources and consequences of gender differences in skills and attitudes that are important in the labor market. A number of studies have examined the importance of "people skills” in which females are widely viewed as having an advantage (e.g., Weinberg 2000; Black and Spitz-Oener 2011; Borghans et al. 2014, Weinberger 2014 and Deming 2016). Another branch of this literature examines sex differences in competitiveness (e.g., Croson and Gneezy 2009, Niederle and Vesterlund 2011, Buser et al. 2014). The gender 
gap in spatial skills is widely acknowledged in other fields. Spatial skills are viewed an important prerequisite to success in STEM occupations, but to our knowledge they have not been the subject of much previous study in economics.

\section{Sex Differences in Spatial Cognition}

As noted in the Introduction, a male advantage in some spatial abilities has been widely documented. In her summary of the literature, Halpern (2012) reports that while there is a male advantage in spatial perception, mental rotation, spatiotemporal ability, and to a lesser extent, spatial visualization, the evidence for abilities related to the generation and maintenance of a spatial image is mixed. Sanders (2013) reports that females have an advantage in remembering the spatial location of objects in an array. Many of these sex differences emerge very early in life (Halpern 2012). The evidence in tables 1 and 2 for tests of mental rotation point to an origin pre high school.

Spatial perception is the ability to identify the vertical or horizontal planes in a stationary display while ignoring irrelevant information. Mental rotation is the ability to envision how objects appear when rotated in two or three dimensional space. Spatial visualization involves multistep processing of spatial input—for example identifying where hole punches through a folded piece of paper will appear when the paper is unfolded. Spatiotemporal abilities involve processing dynamic spatial displays, such as identifying arrival time for a moving object and judging velocity. Generation and maintenance of a spatial image involves performing a task using a spatial image drawn from memory. ${ }^{6}$

One theory of the source of these sex differences is the higher level of androgens males are exposed to prenatally and at very young ages. Higher levels of testosterone in

\footnotetext{
${ }^{6}$ For more detail and examples of associated tests see Halpern (2012).
} 
utero are thought to slow the development of the left side of the brain leading to right side dominance (e.g., Collaer et al. 2007, Peters et al. 2007). Many visual spatial functions are controlled by the right hemisphere of the brain, and there is evidence that spatial abilities are related to the 2D:4D ratio. ${ }^{7}$

A second theory of some of these sex differences is based in evolutionary theories (e.g., Jones et al. 2003). For example, one hypothesis is that females perform better at object location tasks reflecting their historical duties as food gatherers. A complementary hypothesis is that males are better at geographic tasks due to their historical duties as hunters. Sanders (2013) interprets the male advantage in coincidence-anticipation timing as consistent with a hunting past. ${ }^{8}$

A third interpretation of the sex differences in spatial abilities is that they are environmentally determined. Support comes from evidence that the sex difference varies across countries according to some measures of socio-economic development (e.g., Lippa et al. 2008). There is also evidence that spatial cognition is responsive to training (e.g., Miller and Halpern 2013, Hyde 2014). Finally, during childhood boys and girls participate in sex typed activities. Boys participate more in some activities that are thought to promote spatial skills (Halpern 2012).

Proximate environmental factors that lead to population level sex differences in spatial abilities have not been so rigorously investigated. One challenge is that there is little explicit training in spatial skills at the elementary and secondary school levels. Two candidates, which may have different generational relevance, are computer gaming and

\footnotetext{
${ }^{7}$ The 2D:4D ratio, the ratio of the lengths of the second digit to the fourth digit of the hand, is a marker of prenatal androgen exposure levels.

${ }^{8} \mathrm{He}$ also interprets the female performance superiority for stimuli in near space tasks and male superiority for stimuli in far space tasks within a hunter/gatherer perspective.
} 
athletic activity. ${ }^{9}$

There is evidence that both male and female athletes perform better on formal tests of spatial skills than non athletes (e.g., Ozel et al. 2004, Notarnicola et al. 2014). Furthermore, boys participate in sporting activities at higher rates than girls starting at young ages (Cherney and London 2006, Stevenson 2007; Vilhjalmsson and Kristjansdottir 2003 and references therein). Also, research suggests spatial aptitude is responsive to athletic training for both males and females (e.g., Deno 1995, Moreau et al. 2012). Together this evidence provides a basis for suspecting a relationship between boys’ greater participation in sports and higher spatial cognition, but it does not provide a causal link.

\section{Title IX}

Title IX, enacted by Congress in 1972, was part of the "Education Amendments of $1972 "{ }^{10}$ It prohibited discrimination on the basis of sex at federally funded educational institutions. Perhaps its best known impacts have been on high school level and collegiate sports programs. While as Stevenson (2010) notes, the compliance requirements were quite complex, roughly speaking in the sports domain Title IX required high schools and colleges to raise female athletic participation to approximate equality with their male athletic participation by July 1978. Pre Title IX, male athletic participation rates in high school varied considerably by state, while female athletic participation rates were uniformly low. Therefore, the challenge of Title IX compliance

\footnotetext{
${ }^{9}$ While computer gaming and athletic activity, two experiential pastimes associated with males, have garnered much attention, there are numerous female and gender neutral extracurricular activities thought to promote spatial cognition. For example, Newcombe et al (1983) in their catalogue of spatial activities cite pursuits such as horse jumping, drawing and painting, ballet, field hockey, knitting and gymnastics.

${ }^{10}$ Much of the following discussion follows Stevenson (2010).
} 
varied significantly at the state level. This feature, along with an argument that the enactment of Title IX was uncorrelated with unobserved determinants of athletic participation rates and later student outcomes, makes this episode an attractive forum to evaluate the impacts of high school athletic participation.

Stevenson (2010) provides this analysis, showing that female athletic participation rates in high school increase sharply after Title IX came into effect. She reports that female participation rose from under 5 percent pre Title IX to close to 30 percent by the end of the 1970s. This increase in participation was also positively related to a state's pre Title IX male athletic participation reflecting how the compliance target varied at the state level.

Stevenson also provides instrumental variables (IV) estimates of the impact of females’ sports participation on their labor market participation and educational attainment, using pre Title IX male participation rates as an instrument. The estimates indicate that sports participation positively affected both these outcomes. Secondary results indicate that states with greater growth in opportunities for females to play sports saw greater growth of females in "male” and "mixed” occupations relative to female occupations. To the extent that male and mixed employment is positively related to the spatial skill requirements of jobs, this is an initial signal that the increased female sports participation precipitated by Title IX may have increased the spatial content of female employment.

There are potentially many reasons why Title IX led to increased educational attainment and labor market participation. Stevenson (2010) points to possible positive effects of athletic participation on the ability to compete in a controlled environment and 
work in a team setting. Athletics may also enhance self-esteem, create larger social networks and engender more encouragement and attention from adults. Our focus here is on sports' documented impact on spatial skills. Of course, if other skills that are influenced by sports participation are negatively correlated with spatial requirements across jobs, it is possible that we will not see an increase in the spatial content of employment even if women's spatial skills have improved. We investigate this possibility in our robustness checks.

Title IX also changed females' opportunities to participate in sports at the elementary, junior and post secondary school levels. As Stevenson $(2007,2010)$ notes sports participation at the college level is much lower than at the high school level, so any contribution of increased opportunities at the postsecondary level are unlikely to account for a large share of any effect. Potentially more important are the opportunities in elementary schools, which had a much shorter window to comply with the new law-a deadline of July 1976. Therefore, most "post Title IX members” of our analysis samples will have also been exposed to any increased opportunities for female sports participation at the elementary and junior school levels. The sample females' exposure to increased opportunities for sports participation as result of title IX could have started at ages younger than high school entry.

\section{Data and empirical strategy}

Our data on male and female high school sports participation were provided by the National Federation of High Schools (NFHS), which tracks male and female participation by state, sport, sex and year. We use data from the 1971-72 school year to construct pre-Title IX male and female participation rates, and from 1977-78 to construct 
female sports participation rates just prior to the compliance deadline. ${ }^{11}$ We divide the numbers of female or male participants in sports (or a particular sport) by an estimate of either female or male high school enrolment at the state/year level ${ }^{12}$ to produce participation rates. A list of the sports captured by the data, as well as information on the number states offering each sport is provided in the appendix.

To link sports participation to occupational skills, we use data from the 1980 and 2000 Public Use Census samples. We examine outcomes for women aged 25-34 in each year, who have at least a high school education and who are working in the civilian labour force. The 1980 sample will contain individuals who completed high school prior to Title IX, while the 2000 sample will contain individuals who completed high school in a period when states were required to be in compliance with Title IX.

To measure occupational skills, we link 1990 Census occupation codes to measures of skills from the 1991 Dictionary of Occupational Titles. ${ }^{13}$ The DOT, which

${ }^{11}$ Data prior to 1971-72 do not identify female participants. A change in the data collection methods starting with the 1978-79 school year render the data from this year forward not directly comparable to earlier data. Following Stevenson (2010) we omit data for Iowa from the analysis as this state did not start reporting participation by sex until the 1981-82 wave.

${ }^{12}$ High school enrolment by sex is not available for these years at the state level. We simply calculate the numbers of females (males) as 50 percent of the total. Total high school enrolment by state by year is obtained from the National Center for Education Statistics. An alternative strategy followed by Stevenson (2010) is to try to infer sex specific enrolments from reported high school graduation rates in the 1980 and 2000 censuses. As noted by Stevenson, the limitations of this approach include that it also captures GED certification and must use state of birth to identify state of high school, but it also potentially accounts for any increases in female enrolments as a result of increased athletic opportunities. In any event, Stevenson reports that her results are robust to using the 50/50 allocation, which we also find using the alternative.

${ }^{13}$ The DOT codes are at a finer level of occupational detail than the Census occupation coding scheme (so that each Census code contains a number of DOT occupations). We average the DOT ratings across all DOT occupations within a Census code, using occupations' shares of employment as weights. As a result, although our DOT measures are categorical, they are continuous within our data. 
was created by the U.S. Department of Labor, rates each of several thousand occupations along a number of dimensions such as aptitudes, temperaments, environments and physical demands. Our measures of spatial skills from the DOT are the aptitude "spatial" and the physical demand “depth perception”. ${ }^{14}$

The spatial aptitude is, “The ability to think visually of geometric forms and to comprehend the two-dimensional representation of three-dimensional objects. The ability to recognize the relationships resulting from the movement of objects in space” (US Department of Labor 1991). This measurement roughly captures some of the skills of mental rotation and spatiotemporal ability. Optometry is an occupation with a very high level of this aptitude, while insurance, sales is an occupation with a very low level.

Depth perception is, “Three-dimensional vision. Ability to judge distances and spatial relationships so as to see objects where and as they actually are” (US Department of Labor 1991). Examples provided in the coding handbook span spatiotemporal abilities and coincidence anticipation timing skills. Bus driving is an occupation with a high demand of this skill, while sociology is an occupation with a low demand for this skill. Our identification strategy follows Stevenson (2010). Because Title IX applied nationwide, a strategy that simply related pre/post Title IX time series variation in an outcome (e.g., the spatial content of female employment) to corresponding variation in female athletic participation, might possibly be confounded by contemporaneous time varying factors that also affected the outcome. As a result, Stevenson uses an

\footnotetext{
${ }^{14}$ While "physical activity" may suggest either activities such as crouching, or physical capacities such as strength, both or which are rated in this category, the DOT also deems activities such as vision acuity, talking and depth perception as "physical”. A key distinction from "aptitudes" is that physical activities can be measured by their frequency (not present through constant) while aptitudes are measured in terms of percentile ranges relative to a population.
} 
instrumental variables (IV) approach that relates cross state, pre/post Title IX changes in outcomes, to cross state changes (1971-72 to 1977-78) in females’ sports participation, using cross state variation in pre Title IX males' sports participation (in 1971-72) as an instrument. Variation in the "1972” male participation rates captures corresponding variation in the targets states had to pursue to comply with Title IX. Note that the assumption here is the correlation of the change in any outcome with the cross state variation in male sports participation pre Title IX distinguishes a Title IX sports effect from time effects that were concurrent with the enactment of the amendments.

Our main regression equation is

$$
S_{i s c}^{f}=\alpha+\beta P_{s c}^{f}+\delta X_{i s c}+\varepsilon_{i s c},
$$

where $S_{i s c}^{f}$ is the DOT spatial/depth perception rating for the occupation chosen by female $i$ in state $s$ and cohort $c(c=1980,2000), P_{s c}^{f}$ is the high school sports participation rate for females in state $s$ and cohort $c$, and $X_{i s c}$ is a set of controls including state fixed effects, race, cohort ("POST") and age indicators. The key variable, $P_{s c}^{f}$ is instrumented using men's 1972 high school sport participation rate interacted with the POST $(c=2000)$ dummy variable. We standardize the DOT aptitude/skill measures to have a mean of zero and a standard deviation of one. Standard errors are clustered at the state/cohort level.

We also provide direct evidence on the relationship between spatial skills and sports participation using a test of spatial skills from the sample of seniors in the Project Talent data and Seniors Cohort of the High School and Beyond (HSB) dataset. This is the test of three dimensional spatial rotation from the Project Talent survey (e.g., tables 1 and 2) that was administered to the seniors cohort of the HSB. As noted above, the Project 
Talent data are from 1960, while the HSB data are from 1980. Therefore, the Project Talent testing predates Title IX, while the deadline for Title IX compliance is approximately at the midpoint of the high school career of seniors in the HSB. In both cases, we restrict the sample to respondents aged 16-19; this encompasses $95 \%$ of the respondents in the High School and Beyond data, and 97\% of the Project Talent data. We also restrict the sample to respondents with an identifiable race. Our measure of spatial ability in both samples is the number of correct answers on the spatial test, which ranges from 0 to 16 . We standardize this measure separately by year to have a mean of zero and a standard deviation of one. ${ }^{15}$

\section{OLS estimates of the relationship between sports participation and the spatial content of employment}

We begin our analysis by investigating the simple OLS relationship between sports participation and the spatial content of employment at the state level within our census analysis samples. To do this we run the regressions

$$
S_{i s c}=\eta+\phi P_{s c}+\pi X_{i s c}+\omega_{i s c}
$$

pooling men and women together.

The results are reported in table 3. The first estimate for each measure of the spatial content of employment excludes state fixed effects and so captures both the cross section and time series (conditional on a common time effect) variation in the data. In each instance there is a positive and statistically significant relationship between sports participation and the spatial content of employment. For example, a 100 percentage point increase in high school sports participation is estimated to increase the "spatial" aptitude

\footnotetext{
${ }^{15}$ These regressions include three indicators for age and two indicators for race (black and other, with white as the omitted category.)
} 
of employment by 11 percent of a standard deviation and physical demand "depth perception” by almost 14 percent of a standard deviation.

The second estimate for each measure is also conditional on state fixed effects. Therefore, the identification is within state variation in sports participation and the spatial content of employment conditional on the common time effect. In each case the estimate is larger, for the spatial aptitude markedly so. A 100 percentage point increase in sports participation now increases this measure of the spatial content of employment by over 20 percent of a standard deviation.

These estimates are consistent with a hypothesis that sports participation promotes the spatial cognition demanded in certain occupations. However, it may also be true that individuals with higher spatial cognition for other reasons are drawn to both sports while a child, and occupations using spatial skills when an adult.

\section{The effect of Title IX on sports participation and the spatial content of employment}

To address the potential bias in the OLS estimates in tables 3 , we next focus on the increase in females' high school sports participation precipitated by Title IX. We begin estimating the first stage relationship between the change in females' sports participation and males' pre Title IX sports participation. The equation estimated is

$$
P_{s c}^{f}=\theta+\kappa \cdot\left(P O S T \cdot P_{s 1972}^{m}\right)+\lambda X_{s c}+v_{s c}
$$

The result is reported in the top panel of table 4 . The estimated coefficient on the instrument indicates that states that had a 10 percentage point higher Title IX target saw an over 5 percentage point higher increase in female sports participation. The F-statistic for the regression allays any fears about weak instruments. Similar to Stevenson (2010), the result indicates that pre Title IX males' sport participation is a strong predictor of the 
change in females' high school sports participation. It is this estimated increase in females' sport participation that is the basis for our hypotheses for changes in females' spatial employment.

A base set of estimates of the impact of female sports participation on the spatial content of their occupational employment is presented in the bottom panel of table 4. In the first row are the reduced form estimates from regressing the DOT aptitude/skill rating — spatial and depth perception—of females’ employment directly on the instrument and the controls. The estimates on the instrument indicate a negative, insignificant relationship between the pre/post Title IX change in the (DOT) spatial content of females’ employment and males’ pre Title IX sport participation.

The IV estimates in the second row confirm this inference. Each estimate is negative, statistically insignificant and very close to zero. A 100 percentage point increase in female participation is estimated to decrease the spatial aptitude of employment by 0.6 percent of a standard deviation and the depth perception of employment by 1.7 percent of a standard deviation. The conclusion here is that the increase in females' sports participation as a result of Title IX, had no impact on the spatial content of their employment.

The "failure" of the IV estimates to yield a positive impact of female sports participation on the spatial content of women's occupational employment is clearly demonstrated in figures 1 and 2. Here we graph the state level changes in our DOT measures on male sports participation in 1972. These graphs capture the reduced form relationship between the instrument and our measure of the change in the spatial content of the jobs females hold. There was an increase in the DOT spatial content of female 
employment over the 1970s, but it bears little relationship to the cross sectional levels of pre Title IX male sports participation. The change in the DOT depth perception is on balance negative, but the only states experiencing positive growth are those with the lowest targets for Title IX compliance. Given that this cross state variation in male participation is a strong predictor of the change in females' sports participation over the period Title IX was enacted, there is little evidence here that this increase in female sports participation lies behind the increase in "spatial employment".

\section{Direct Evidence of the Impact of Sports Participation on Spatial Skills}

A potential qualification to this conclusion is that our findings could be influenced by any changes in females' labor market participation between our pre and post Title IX samples. Note that we are not using any secular changes in the spatial content of female employment for identification. Stevenson (2010) provides evidence, however, that there are increases of females' participation correlated with pre Title IX male’s sport participation-Title IX induced sports participation increased females’ participation in the labor market. ${ }^{16}$ One could construct a story in which sport participation increases females’ spatial skills, but also spatial skills are positively related to labor market participation, and the entrance of workers with lower skills brought down the average level of skills in the sample working population. ${ }^{17}$

To try to address this issue we examine a direct measure of spatial skills for

\footnotetext{
${ }^{16}$ Stevenson (2010) reports that the labor force participation of 24-34 year old women rose from $62 \%$ to $72 \%$ between 1980 and 2000, and roughly 4 percentage points of this increase could be attributed to Title IX.

${ }^{17}$ For example, suppose that the positive effects of sports participation on spatial skills are confined to the new entrants to the labor force, whose higher levels of these skills are nevertheless lower than unaffected labor force participants. More plausibly the impact of sports participation on spatial skills is more widely distributed, but nevertheless the net effect of the increase in these skills and the increase in participation is a lower level of spatial skills among market participants.
} 
graduating seniors from the Project Talent and HSB data sets. Although conditional on continuing in high school until grade 12, these samples do provide a more temporally stable population. ${ }^{18}$

In Table 5 we report reduced form and IV estimates of the impact of Title IX induced sports participation on the spatial test score. ${ }^{19}$ Both the reduced form and IV specifications estimates are small, negative and statistically insignificant. Figure 3 shows the reduced form specification visually; the estimated regression line linking changes in females' spatial test scores to male 1972 sports participation is almost perfectly flat. These results strongly echo the results in table 5 for the spatial content of female employment.

Note that by using the Project Talent data as our pre Title IX observation, these estimates also capture any changes in spatial skills over the 1960's to the extent they are correlated with pre Title IX male sports participation. In attempt to net out any 1960s change in spatial skills due to changes in female sports participation, we have reestimated the reduced form omitting states with unusually high rates of female sports participation in 1972. The results are almost identical to those in table $6 .{ }^{20}$

We have also re-estimated the reduced form substituting Grade 10 Project Talent

${ }^{18}$ Heckman and Lafontaine (2010) report that the high school graduation rate increased by just over 5 percentage points between 1960 and 1980 .

19 The first stage for the IV estimates in Table 5 is nearly identical to the first stage presented in Table 4; the coefficient on the instrument is 0.509 (the same as in Table 4) and the F-statistic is 82.7, slightly stronger than the 80.1 shown in Table 4 . The difference between the first stages arises from the relative weight of each state in the regression, which may differ because of the distribution of respondents across states; in practice, this matters very little.

20 The coefficient on the reduced form estimates is -0.054 and insignificant if we exclude the top four states (which have participation rates of $0.15-0.2$, as opposed to less than 0.1 for all other states.) If we exclude all states with sports participation above 0.05 (21 states and 29 percent of observations), the coefficient is 0.058 , and is still statistically insignificant. 
test scores for the grade 12 results. $^{21}$ As noted above, high schools graduation rates are marginally higher in 1980 than in 1960. By substituting a lower grade's scores for the 1960 observations we attempt to better hold constant the underlying population being tested. The results are quite similar using the grade 10 scores: the coefficient on the instrument in the reduced form is -0.073 , as opposed to -0.053 in our main results, and remains insignificant. $^{22}$

\section{Robustness Checks and Alternative Hypotheses}

In this section, we investigate the possibility that there are pre-existing trends in the spatial content of women's employment that are correlated with men’s pre Title IX sports participation in 1972. Next, we consider two alternative explanations of our conclusion that the increase in females' sports participation as a result of Title IX had no impact on their relative spatial skills. First, we explore the possibility that Title IX had no impact on females' spatial skills because it increased participation in sports that have little spatial content. Second, we investigate a hypothesis of how Title IX might causally affect females' spatial skills, with no concurrent effect on the spatial content of their occupations. This could occur if Title IX had even stronger impacts on females' levels of other job-relevant aptitudes that are negatively correlated across occupations with spatial skills.

Robustness checks

An a priori objection to using the Title IX framework to evaluate the contribution

${ }^{21}$ While the females' spatial scores change by grade, our focus is the relative pre/post change in scores correlated by males' pre Title IX sports participation, so this should not be a significant consideration as long as the grade effect is uniform across states.

${ }^{22}$ If we instead use the scores for grade 11 students the reduced form estimate is -0.028 and statistically insignificant. Finally, if we use grade 9 grades, a perhaps less advisable strategy due the higher presence of retentions in this grade (Heckman and Lafontaine 2010) the reduced form estimate is 0.014 and statistically insignificant. 
of sports participation to spatial cognition is if there was some pre existing relationship between males’ pre Title IX high school sport participation levels by state (the instrument) and trends in the spatial content of state employment. ${ }^{23}$ For example, states with higher male sport participation rates, and thus higher targets under Title IX, might also have greater growth in (female) employment with high levels of spatial skills.

To test for such a relationship, we estimate a placebo reduced form regression of pre Title IX employment outcomes on the instrument. These regressions are of the same format as in table 4, except now we measure the spatial content of females’ employment using data from the 1970 and 1980 censuses, rather than the 1980 and 2000 censuses. The 1970 and 1980 data exclusively capture individuals who completed high school pre Title IX.

The results are reported in the top panel of table 6. The estimate for the spatial aptitude is positive, but small and statistically insignificant. The estimate for depth perception is also positive, modest and marginally statistically significant. There is no strong evidence that females in states with high pre Title IX males’ sport participation experienced substantially higher growth of occupational employment with a high spatial content.

Although it does not appear that male sports participation in 1972 was correlated with underlying changes in the labor market that would affect the spatial content of women's jobs, it is worth noting that any such changes would also be likely to affect men. In contrast, Title IX provided a shock to the sports participation of women only. We next adopt a difference-in-differences framework to evaluate how any common trends

${ }^{23}$ Stevenson (2010) provides further discussion of the factors driving pre Title IX variation in males' sports participation across states, including school size and climatetime invariant fixed factors. 
over the decade Title IX came into effect changed the spatial content of employment.

In bottom panel of table 6 we report the results of a difference-in-differences regression relating changes in the spatial content of women's jobs to changes in the spatial content of men’s jobs in the same state, pre- and post-Title IX. The regression equation is

$$
\begin{aligned}
S_{i s c}^{f}= & \tau+\varphi \cdot \text { Female }+\mu \cdot \text { POST }+\rho \cdot \text { Female } \cdot \text { POST }+\psi \cdot \text { POST } \cdot P_{s 1972}^{m}+ \\
& \gamma \cdot \text { POST } \cdot P_{s 1972}^{m} \cdot \text { Female }+\vartheta X_{i s c}+\iota_{i s c}
\end{aligned}
$$

The coefficient of interest is $\gamma$, which captures any differential relationship between male sports participation in 1972 and changes in the spatial content of women's jobs, relative to the same relationship for men in the same state. The estimates of this coefficient in table 9 are statistically insignificant and very close to zero. A 100 percentage point increase in male sports participation in 1972 was associated with an increase in female spatial aptitude of 1.5 percent of a standard deviation, relative to men in the same state; for depth perception, the effect is 2.2 percent of a standard deviation. Neither estimate is statistically significant.

\section{Differences across sports in spatial training}

We have shown that the overall increase in female sports participation induced by Title IX had no effect on the spatial content of women's jobs or on a spatial test scores of high school seniors, and have interpreted this as suggesting that sports do not play a large role in explaining male-female differences in spatial aptitude. A further objection to this interpretation is that not all sports participation may be equally productive at increasing spatial cognition. For example, the so called "ball” sports may be more significant

promoters of spatial cognition than sports like running or swimming. It is possible that 
Title IX increased females’ sports participation, but not in sports that matter to spatial skills. Alternatively, Title IX may have increased participation in sports that matter, but our instrument misses this growth. In either case our IV estimates would be dominated by increases in participation in sports that have little relationship to our outcomes of interest.

In table 7 we investigate this hypothesis. We list the pre and post Title IX levels of female participation in the different sports in our sample. Pre Title IX participation in almost all sports was very low; close to zero in all sports except basketball, track and field and tennis. Total female participation in all sports was 3.3 percent.

Post Title IX we see participation growth in many sports. Basketball and track and field stand out, but so do volleyball and to a lesser extent baseball and tennis. In 1978 total female participation in these sports is 28.8 percent.

The relationship between the increase in female participation in these specific sports and our instrument is explored in table 8. Here we present the "first stage" relationship between females' participation in specific sports and males' pre Title IX sports participation in 1972. With a few exceptions our instrument picks up the increases in participation seen in table 7. For example, the largest estimates are for basketball and track and field. What our instrument "misses” is the increase in females' participation in baseball. ${ }^{24}$

\footnotetext{
${ }^{24}$ To try to exploit any increase in baseball due to Title IX we might use male sportspecific participation as an instrument for female participation in the same sport (e.g., predict female baseball participation with pre Title IX male baseball participation.) While Title IX does not mandate increases in female participation in specific sports, pre Title IX male participation in specific sports may capture "existing capacity" and thus the least cost path to Title IX compliance in a given state. The increase in female baseball participation predicted by pre Title IX male baseball participation has no effect on either spatial aptitude or depth perception of females' occupational employment (results
} 
We are not aware of any generally accepted ranking of sports by their potential to develop spatial aptitude. Research on spatial activities provides some guidance. Newcombe et al. (1983) developed a "spatial activity questionnaire” by asking undergraduates to rank 231 common activities for both the spatial ability they required and whether they were traditionally masculine, feminine or neutral activities. All of the sports we consider, with the exceptions of swimming and cross country, were part of a list of 81 spatial activities as designated by at least $75 \%$ of the judges. ${ }^{25}$

Ozel et al. (2004) investigate the relationship between sport and mental rotation tasks, distinguishing between open skill (e.g., basketball, badminton, soccer, judo) and closed skill (swimming, track and field, archery, body building and gymnastics) sports. They hypothesize that practitioners of open skill sports will be quicker in the cognitive processing of the task response. While the open skill group do exhibit faster response, the difference from the closed skill group is not statistically significant. Moreau et al. (2012) investigate the impact of the practice of wrestling and running on performance in mental rotation tasks. They hypothesize that a sport that involves the mental manipulation of objects in three dimensional space (wrestling) would have a greater impact of this dimension of spatial ability than one that does not (running). Using random assignment of university level students to the two sports, the authors found greater improvement in mental rotation test scores among the students practising wrestling, although the runners also showed improvement.

ESPN has produced a ranking of 60 different sports along ten different

available upon request).

${ }^{25}$ Only certain track and field activities are included in the list. One notable feature of the development of this questionnaire was the systematic attempt to enumerate the universe of activities practiced by high school and college students. 
dimensions: endurance, strength, power, speed, agility, flexibility, nerve, durability, hand-eye coordination and analytic. The ratings are the average score out of 10 given to each sport by a panel of eight experts, which included two members of the United States Olympic committee, two professors of kinesiology, a professional athlete and three sports journalists. While spatial aptitude is not ranked explicitly, we focus on the analytic aptitude, "The ability to evaluate and react appropriately to strategic situations. Example: Joe Montana reading a defense; basketball point guard on a fast break”. ${ }^{26}$ This description suggests an ability to read fluid three dimensional environments, which involves elements of spatiotemporal skills and coincidence anticipation timing. There is also an element of reactive speed, but that skill is explicitly evaluated in another the dimension, hand—eye coordination. Sports such as hockey, soccer and basketball rank highest in analytic aptitude, followed by football, tennis, golf and volleyball. ${ }^{27}$ Lower ranked sports include swimming and multiple distances running. While the analytic aptitude as defined also involves some "thinking tasks", the examples provided suggest these tasks are in reaction to initial spatial perception, and the ranking of sports by this measure is in rough accord with alternative identifications of spatial sports.

In tables 7 and 8 , we see strong increases in females' participation in basketball and volleyball—sports that we might expect count as spatial aptitude training. Tennis might also be included in this group. The results in table 8 indicate that together these three sports represent 60 percent of the first stage estimate in table 4. Gymnastics and track and field are the other two sports with "large” first stage estimates. Gymnasts have been demonstrated to have better mental rotation abilities in certain dimensions than non

${ }^{26}$ Accessed at http://espn.go.com/espn/page2/sportSkills on February 26, 2016.

${ }^{27}$ Wrestling receives a similar ranking to golf. 
athletes (Jansen and Lehmann 2013). Gymnastics falls just below the midpoint in the ESPN ranking of analytic aptitude and is an element of Newcombe et al.’s (1983) spatial activity questionnaire.

Track and field is harder to categorize because it includes very different activities. For example, in the ESPN ranking distance running and pole vault are just below the midpoint, while sprints and high jump are near the bottom. That said, both high jumping and pole vaulting are elements of the spatial activity questionnaire.

Overall, it is not obvious that the increase in female participation post Title IX, or that part of it correlated with cross state variation in males’ participation in 1971, is concentrated in sports that have no spatial content. In fact, at least a majority of the increase picked up by the instrument is in sports considered to have above average spatial demands.

As a summary of the discussion, we use the ESPN aptitude rating for sports, along with the sport participation rate data, to construct an average rating for this aptitude by state, sex and year. Specifically, the average rating for the analytic aptitude $a$ is

$$
R_{s c}^{a g}=\sum_{j} P_{s c j}^{g} \cdot R_{j}^{a}
$$

where $g$ indexes gender, $s$ indexes states, $c$ indexes cohort and $j$ indexes sports. $R_{j}^{a}$ is the ESPN ranking of $a$ in sport $j, P_{s c j}^{g}$ is the state level participation rate of cohort $c$ and gender $g$ in sport $j$. The aggregate rankings are standardized to have a mean of zero and a standard deviation of 1 .

In the top panel of table 9, we report the first stage relationship between this measure of the content of females' sports participation and males' pre Title IX sport participation. Echoing the results in table 4 there is a strong positive relationship. A state 
where the pre Title IX male’s sport participation was 10 percent higher would see a 0.3 standard deviation higher increase in the analytic content of females’ sport participation.

The corresponding IV estimates are reported in the bottom panel of the table. They indicate that weighting the increase in females' sports participation in this way does little to change the inference in table 4 . The estimated relationship between the analytic content of females' sports participation and the spatial content of their employment is small, negative and statistically insignificant, mirroring the results in table 4.

Title IX and the development of non-spatial skills

Title IX induced sports participation led to an increase in the educational attainment of women (Stevenson 2010), and so had an impact on some cognitive or noncognitive skills. It is possible that an improvement in these other skills could mask any effect of Title IX on spatial aptitude, because groups of skills tend to be correlated across jobs. For example, if the spatial demands of a job are negatively correlated with its required educational or interpersonal skills, then as a result of Title IX women may select into jobs with lower spatial aptitude even if their spatial abilities improved.

To investigate whether Title IX induced sports participation affected the overall skill profile of jobs chosen by women in this way, we first perform a principal components analysis of a selection of job characteristics, to discover how these are correlated with spatial skills across occupations. Stevenson (2007) notes that sports participation is thought to enhance leadership and interpersonal skills, as well as endurance. Also Stevenson (2010) shows the direct effect of Title IX on females' educational attainment. Not all these aptitudes/skills are captured by the DOT data. To measure cognitive demands we use the DOT rating "general educational development - 
reasoning”, although the results are very similar if we use GED math or language. To measure interpersonal demands, we use the DOT variable "temperament - dealing with people.” ${ }^{28}$ Finally for physical demands, we use the DOT physical strength rating. In the top panel of table 10 we report the results of our principal component analysis of these skills plus our spatial measures across occupations. For each component we report the weightings for each DOT skill and the associated eigenvalue. The first component appears to capture the overall physicality of a job; it positively weights physical strength and the spatial aptitudes, and negatively weights reasoning and people skills. The occupations with the highest rating on this component are those related to construction and trades; the occupations with the lowest rating are judges and lawyers. The second component appears to reflect more abstract spatial skills, with high weightings on reasoning and both spatial measures, and low or negative weightings on interpersonal skills and physical strength. Occupations at the highest levels of this component include dentists, architects and physicists. The other components are more difficult to interpret, but are also relatively unimportant. The first two components are the only ones with eigenvalues greater than one (generally considered the threshold at which components are retained in this type of analysis), and together explain about $80 \%$ of the joint variance in the five measures.

In the bottom panel of the table we report the results from reduced form regressions of each component (which are standardized to have mean zero and standard deviation of one) on males pre Title IX sports participation. Most of the estimates are small and statistically insignificant. The exception is the estimate for component 3,

${ }^{28}$ Baker and Cornelson (2016) show that it makes very little difference using alternative measures of people skills. 
which has little relationship to either measure of spatial skills. Even for this component, males pre Title IX sports participation accounts for very little of the variance: the $\mathrm{R}^{\wedge} 2$ for this regression is 0.003 . On net, it does not appear that males' pre Title IX sports participation affected the general skill profile of jobs chosen by women, particularly with respect to spatial skills. It seems unlikely, then, that changes to educational attainment, interpersonal or physical skills are offsetting any tendency towards employment in occupations with higher spatial requirements.

\section{Conclusions}

Extra curricular activities are a leading environmental explanation of the emergence of sex differences in spatial cognition at young ages. While the sex difference in computer gaming is a working hypothesis for cohorts of workers currently entering the labor market, it cannot be the source of this sex difference for older cohorts of workers (e.g., table 1). However, computer gaming is just a current episode of the long history of sex typed activities in childhood. A promising explanation from earlier years is boys' higher rates of participation in sports and play. We exploit the effects of Title IX on females' sports participation, what Stevenson (2007) observes is “....arguably the largest change to mass participation in sports history”, to test this hypothesis. As such, Title IX is also arguably the largest change to childhood sex typed activities of recent times.

We find no evidence that the massive increase in female high school sports participation following the enactment of Title IX increased spatial cognition among women as captured either by their occupational choices or direct tests of three dimensional spatial skill. Although the skill profile of jobs chosen by women did change over this period, the change was similar across states with very different levels of Title 
IX-induced female sports participation. This suggests that high school sports participation is not an important determinant of spatial cognition related, gender differences in occupational choice. Our results also cast doubt on a hypothesis that sports participation is the source of sex differences in three dimensional spatial rotation.

It is important to note that our results do not imply that sports training does not increase spatial cognition - there is evidence from random control trials that it does (e.g., Moreau et al. 2012). Among other considerations, there are likely differences between the training received in an RCT and through a more passive participation in school sports. Also, because spatial skills are multidimensional, it is possible that Title IX increased spatial skills not spanned by our DOT measures or by the tests scores in the Project Talent and HSB surveys.

Finally, while Title IX applied to elementary and middle schools, we are not aware of data that would allow us to evaluate its impact at this level. To the extent that Title IX's targets and the compliance of elementary schools at the state level echoed targets and compliance at the high school level, our empirical strategy should capture any impact of the resulting increase in females' sports participation at younger ages. However, it is possible that it is sports participation at these younger ages that is critical for spatial cognition. Then, if Title IX compliance in elementary schools was low our analysis does not offer a fair evaluation of the sports participation hypothesis. Alternatively, if Title IX's impact at the state level differed markedly in elementary and high schools, our analysis might miss an effect of the law (and sports participation) on spatial development. Subject to these qualifications the balance of our evidence casts some doubt on sports participation as the source of sex differences in some spatial skills. 
Although we are unable to make a link to Title IX, both females' three dimensional spatial cognition and the spatial content of their occupations increased relative to males' over the period of study. The Project Talent and HSB data reveal that the sex difference in the three dimensional spatial rotation test declined by 35 percent among high school seniors between 1960 and $1980 .{ }^{29}$ The gender difference in the DOT measures declined by 22.3 percent for spatial aptitude and 11.0 percent for depth perception between our 1980 and 2000 cohorts. $^{30}$ Spatial cognition has been relatively understudied by economists, but is increasingly acknowledged as both a correlate of the gender segregation of employment and a key to entry to jobs in the STEM sector. An explanation of recent changes in the spatial skills of males and females remains an important topic for future research.

\footnotetext{
${ }^{29}$ In 1960 the male/female difference in the test of three dimensional spatial ability was a statistically significant 0.388 of a standard deviation, while in 1980 it was a statistically significant 0.253 .

${ }^{30}$ In 1980, the male-female difference in occupational spatial aptitude was a statistically significant 0.730 standard deviations; by 2000, it was 0.567 standard deviations. The differences for depth perception were a statistically significant 0.857 standard deviations in 1980, and 0.764 standard deviations in 2000.
} 


\section{Appendix}

The NFHS data contain information on 47 sports for the years 1971 and 1978 (counting close variants of the same sport, such as fast and slow softball, as a single sport.) Our measure of total sports participation for both boys and girls is the sum of participation across all of these sports.

Table A1 shows the number of states with positive participation in each of the sports listed in the NFHS (with indications for sports that are combinations of different variants.) The sports that are individually identified in parts of the analysis are shown in bold font. 
Table A1: number of states with positive participation, by sport

\begin{tabular}{|c|c|c|c|c|}
\hline & \multicolumn{4}{|c|}{ Number of states with positive participation } \\
\hline & Male, 1971 & Male, 1978 & Female, 1971 & Female, 1978 \\
\hline Archery & 0 & 1 & 0 & 6 \\
\hline Badminton & 2 & 2 & 0 & 8 \\
\hline $\begin{array}{l}\text { Baseball (baseball } \\
+ \text { softball) }\end{array}$ & 47 & 47 & 5 & 38 \\
\hline Basketball & 51 & 51 & 28 & 50 \\
\hline Bowling & 13 & 10 & 2 & 11 \\
\hline Canoeing & 0 & 1 & 0 & 0 \\
\hline Cheerleading & 0 & 0 & 0 & 1 \\
\hline Crew & 0 & 2 & 0 & 1 \\
\hline Cross country & 48 & 50 & 2 & 2 \\
\hline Curling & 2 & 1 & 0 & 0 \\
\hline Decathlon & 3 & 5 & 0 & 0 \\
\hline Drill Teams & 0 & 3 & 0 & 6 \\
\hline Fencing & 0 & 6 & 0 & 5 \\
\hline Football & 51 & 51 & 0 & 0 \\
\hline Golf & 48 & 47 & 4 & 36 \\
\hline Gymnastics & 37 & 34 & 21 & 43 \\
\hline Handball & 0 & 1 & 0 & 0 \\
\hline $\begin{array}{l}\text { Hockey (field + } \\
\text { floor + ice) }\end{array}$ & 15 & 18 & 2 & 18 \\
\hline Judo & 0 & 1 & 0 & 1 \\
\hline Lacrosse & 4 & 10 & 1 & 8 \\
\hline Pentathlon & 0 & 1 & 0 & 2 \\
\hline Physical fitness & 0 & 1 & 0 & 1 \\
\hline Polo & 0 & 1 & 0 & 0 \\
\hline Racquetball & 0 & 0 & 0 & 0 \\
\hline Riflery & 4 & 10 & 0 & 7 \\
\hline Rugby & 0 & 0 & 0 & 0 \\
\hline Sailing & 0 & 1 & 0 & 1 \\
\hline Ski - downhill & 16 & 13 & 8 & 13 \\
\hline Ski - cross-country & 0 & 1 & 0 & 1 \\
\hline Soccer & 25 & 29 & $\mathbf{0}$ & 16 \\
\hline Soft tennis & 0 & 1 & 0 & 1 \\
\hline Speedball & 0 & 0 & 0 & 1 \\
\hline Speed skating & 0 & 1 & 0 & 0 \\
\hline Swimming & 43 & 4 & 26 & 44 \\
\hline $\begin{array}{l}\text { Synchronized } \\
\text { swimming }\end{array}$ & 0 & 0 & 0 & 1 \\
\hline Table tennis & 0 & 1 & 0 & 2 \\
\hline Tennis & 48 & 51 & 32 & 48 \\
\hline $\begin{array}{l}\text { Track (indoor + } \\
\text { outdoor) }\end{array}$ & 51 & 51 & 15 & 49 \\
\hline Volleyball & 26 & 12 & 6 & 46 \\
\hline Waterpolo & 2 & 7 & 0 & 1 \\
\hline Weight lifting & 0 & 2 & & \\
\hline Wrestling & 47 & 48 & 0 & 0 \\
\hline
\end{tabular}




\section{References}

Baenninger, Maryann and Nora Newcombe, (1989) "The Role of Experience in Spatial Test Performance: A Meta-Analysis” Sex Roles, 20(5/6), 327-344.

Baker, Michael and Kirsten Cornelson (2016) “Gender Based Occupational Segregation and Sex Differences in Sensory, Motor and Spatial Aptitudes”, NBER Working Paper 22248.

Bjorklund, David F. and Rhonda Douglas Brown (1998), "Physical Play and Cognitive Development: Integrating Activity, Cognition, and Education, Child Development, 69(3) 604-606.

Black, Sandra and Alexandra Spitz-Oener, (2010.) "Explaining women's success: technological change and the skill content of women's work.” The Review of Economics and Statistics 92(1) 187-194.

Borghans, Lex, Ter Weel, Bas and Bruce A. Weinberg, (2014) "People Skills and the Labor-Market Outcomes ‘of’ Underrepresented Groups”, Industrial and Labor Relations Review 67(2) 287-334.

Buser, Thomas, Muriel Niederle and Hessel Oosterbeek, (2014) “Gender, Competitiveness and Career Choices,” Quarterly Journal of Economics, 129(3), 1409-1447

Cherney Isabelle D., (2008) “Mom, Let Me Play More Computer Games: They Improve My Mental Rotation Skills” Sex Roles, 59:776-786

Cherney Isabelle D. and Kamala London (2006) "Gender-linked Differences in the Toys, Television Shows, Computer Games, and Outdoor Activities of 5- to 13-year-old Children, Sex Roles, 54, 717-726.

Collaer, M. L., Reimers, S., and Manning, J. T. (2007) “Visuospatial performance on an Internet line judgment task and potential hormonal markers: Sex, sexual orientation, and 2D:4D” Archives of Sexual Behavior, 36, 177-192.

Connellan, J., Baron-Cohen, S., Wheelwright, S., Batki, A. and Ahluwalia, J.: 2000, Sex differences in human neonatal social perception, Infant Behavior and Development 23(1), 113-118.

Connolly, Thomas M., Boyle, Elizabeth A., MacArthur, Ewan, Hainey, Thomas and James M. Boyle, (2012) "A systematic literature review of empirical evidence on computer games and serious games”, Computers and Education, 59(2) 661-686.

Croson, Rachel, and Uri Gneezy, (2009) “'Gender Differences in Preferences,'” Journal of Economic Literature, 47, 448-474. 
Crawford, Mary and Roger Chaffin, (1997) "The Meanings of Difference: Cognition in Social and Cultural Context” in Caplan, Paula J., Crawford, Mary, Hyde, Janet Shibley and Hohn T.E. Richardson, Gender Differences in Human Cognition, New York: Oxford University Press, 81-130.

Deming David J. (2015) "The Growing Importance of Social Skills in the Labor Market" NBER Working Paper No. 21473

Deno, John A. (1995). The relationship of previous experiences to spatial visualization ability. Engineering Design Graphics Journal, 59(3), 5-17.

Halpern, Diane F. (2012), Sex Differences in Cognitive Abilities: 4th Edition, New York, NY: Psychology Press.

Halpern, Diane F. Benbow, Camilla P., Geary, David C. Gur, Ruben C., Hyde, Janet Shibley and Morton Ann Gernsbacher, (2007) "The Science of Sex Differences in Science and Mathematics” Psychological Science in the Public Interest 8(1): 1-51.

Heckman, James J. and Paul A. Lafontaine, (2010) "The American High School Graduation Rate: Trends and Levels”, Review of Economics and Statistics, 92(2), 244-262.

Hyde, Jane Shibley, (2014) “Gender Similarities and Differences” Annual Review of Psychology, 65(3) 373-398.

Jansen Petra and Jennifer Lehmann (2013) "Mental rotation performance in soccer players and gymnasts in an object-based mental rotation task", Advances in Cognitive Psychology 9(2): 92-98.

Jones, Catherine M., Braithwaite, Victoria A. and Susan D. Healy (2003) "The Evolution of Sex Differences in Spatial Ability”, Behavioral Neuroscience 117(3) 403-411.

Lippa, Richard A., Collaer, Marcia L. and Michale Paters, (2008) "Sex Differences in Mental Rotation and Line Angle Judgments Are Positively Associated with Gender Equality and Economic Development Across 53 Nations”, Archives of Sexual Behavior, 39(4) 990-7.

Miller, David I. and Diane F. Halpern, (2013), "Can spatial training improve longterm outcomes for gifted STEM undergraduates?” Learning and Individual Differences, 26 141-152.

Moreau, David, Clerc, Jérome, Mansy-Dannay, Annie and Alain Guerrien, (2012) "Enhancing Spatial Ability Through Sport Practice” Journal of Individual Differences 33(2) 83-88.

Newcombe, Nora, Bandura, Mary M. and Dawn G. Taylor, (1983) “Sex Differences in 
Spatial Ability and Spatial Activities”, Sex Roles, 9(3), 377-386.

Niederle, Muriel, and Lise Vesterlund, (2011) “Gender and Competition,” Annual Review of Economics, 3, 601-630.

Notarnicola, Angela, Maccagnano, Giuseppe, Pesce, Vito, Tafuri, Silvio, Novielli, Grazia and Biagio Moretti1, (2014) "Visual- spatial capacity: gender and sport differences in young volleyball and tennis athletes and non-athletes” $B M C$ Research Notes, 21 7-57

Ozel, Sylvie, Larue, Jacques, and Corine Molinaro, (2004) "Relation Between Sport and Spatial Imagery: Comparison of Three Groups of Participants” The Journal of Psychology, 2004, 138(1), 49-63

Peters, M., Manning, J. T., and Reimers, S. (2007). The effects of sex, sexual orientation, and digit ratio (2D:4D) on mental rotation performance. Archives of Sexual Behavior, 36, 251-260.

Sanders, Geoff (2013) "Sex Differences in Motor and Cognitive Abilities Predicted from Human Evolutionary History with Some Implications for Models of the Visual System”, The Journal of Sex Research, 50:3-4, 353-366.

Sherman, J_ A. "Problem of sex differences in space perception and aspects of intellectual functioning” Psychological Review, 1967, 74, 290-299.

Sorby, Sheryl A., (2009) "Educational Research in Developing 3 - D Spatial Skills for Engineering Students”, International Journal of Science Education, 31(3), 459480.

Stevenson, Betsey, (2007) “Title IX and the Evolution of High School Sports,” Contemporary Economic Policy 25(4) 486-505

Stevenson, Betsey, (2010) "Beyond the Classroom: Using Title IX to Measure the Return to High School Sports" The Review of Economics and Statistics, 92(2): 284-301.

U.S. Department of Labor Employment and Training Administration (1991), The Revised Handbook for Analyzing Jobs, Washington D.C.

Vilhjalmsson, Runar and Gudrun Kristjansdottir (2003) "Gender differences in physical activity in older children and adolescents: the central role of organized sport" Social Science and Medicine 56(2) 363-374.

Weinberg, Bruce (2000) “Computer Use and the Demand for Female Workers”, Industrial and Labor Relations Review, 53(2), 290-308.

Weinberger, Catherine, (2014) “The Increasing Complementarity between Cognitive and 
Social Skills”, Review of Economics and Statistics 96(5), 849-861. 
Figure 1: Males' pre Title IX sports participation and the change in the average DOT “spatial” content of females' occupational employment by state

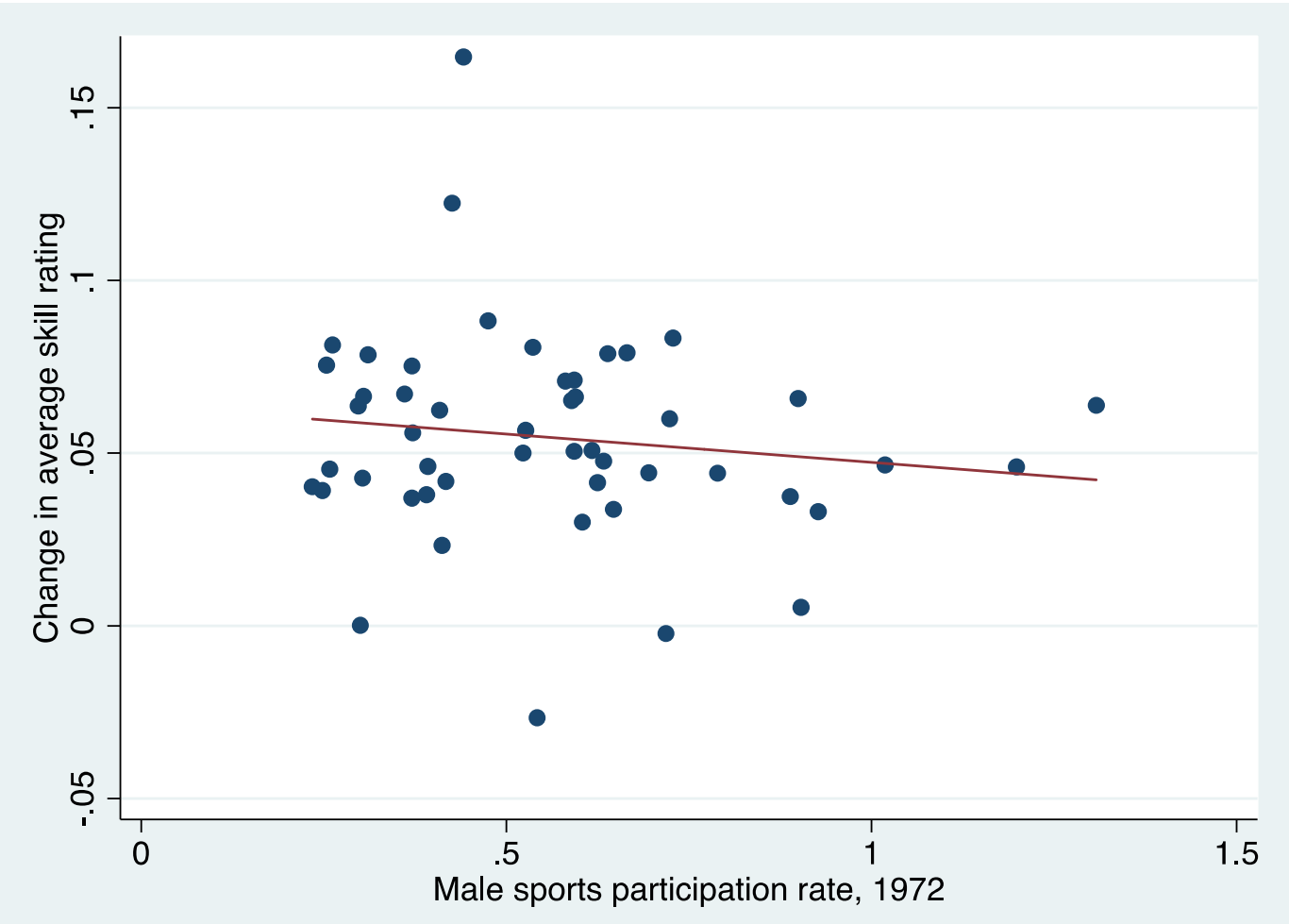

Notes: Notes: Authors' calculations from census, DOT, NFHS and NCES data. Each point represents the average change in the DOT aptitude spatial in females' employment between the 2000 and 1980 census cohorts for a given state, plotted against the male sports participation rate in 1972. (Note that the total sports participation rate can be greater than one, because individuals may be counted in more than one sport.) 
Figure 2: Males' pre Title IX sports participation and the change in the average DOT “depth perception” content of females' occupational employment by state

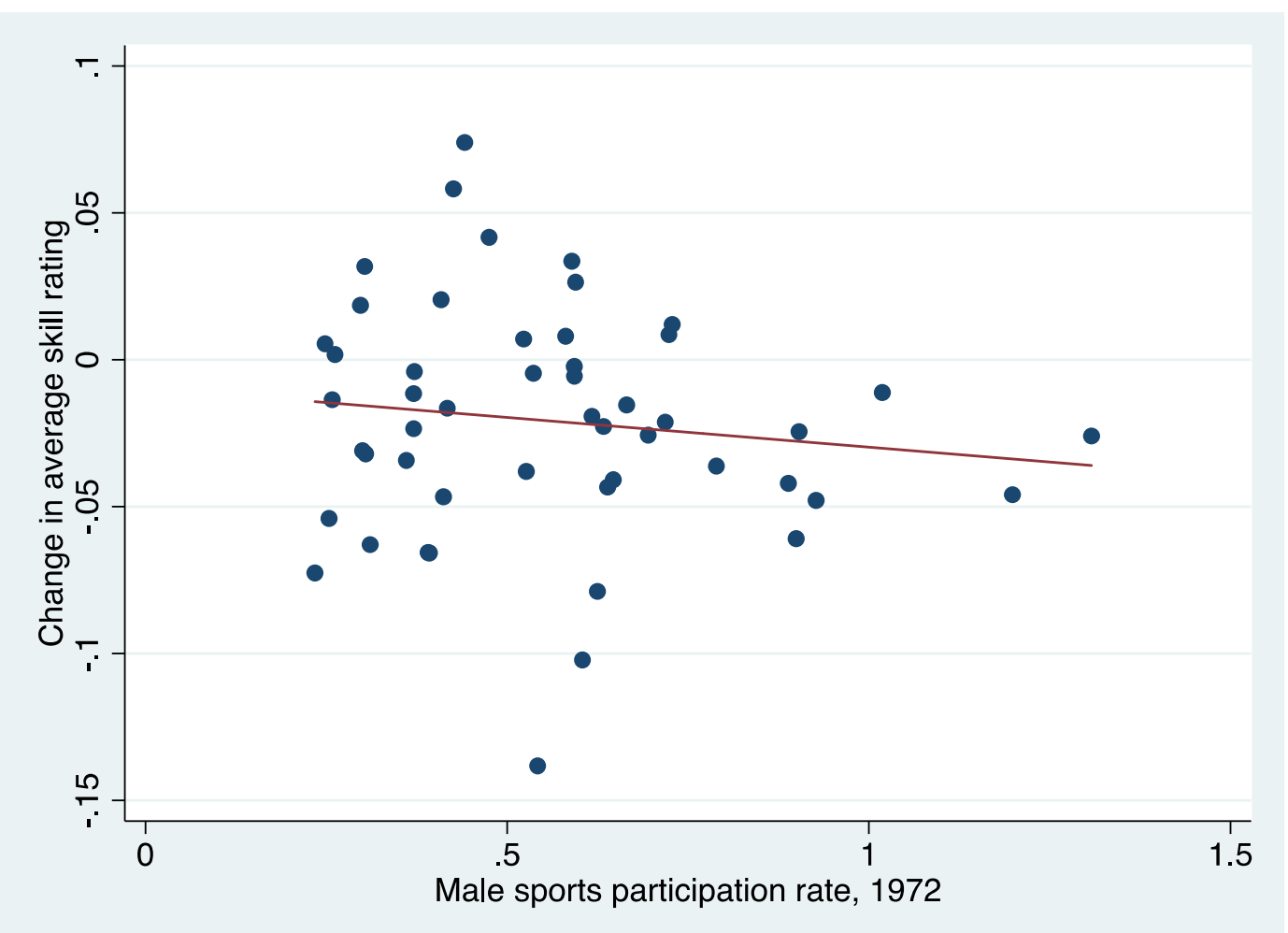

Notes: Authors' calculations from census, DOT, NFHS and NCES data. Each point represents the average change in the DOT physical demand "depth perception" in females' employment between the 2000 and 1980 census cohorts for a given state, plotted against the male sports participation rate in 1972. (Note that the total sports participation rate can be greater than one, because individuals may be counted in more than one sport.) 
Figure 3: Males' pre Title sports participation and the change in females' 3D spatial test score by state

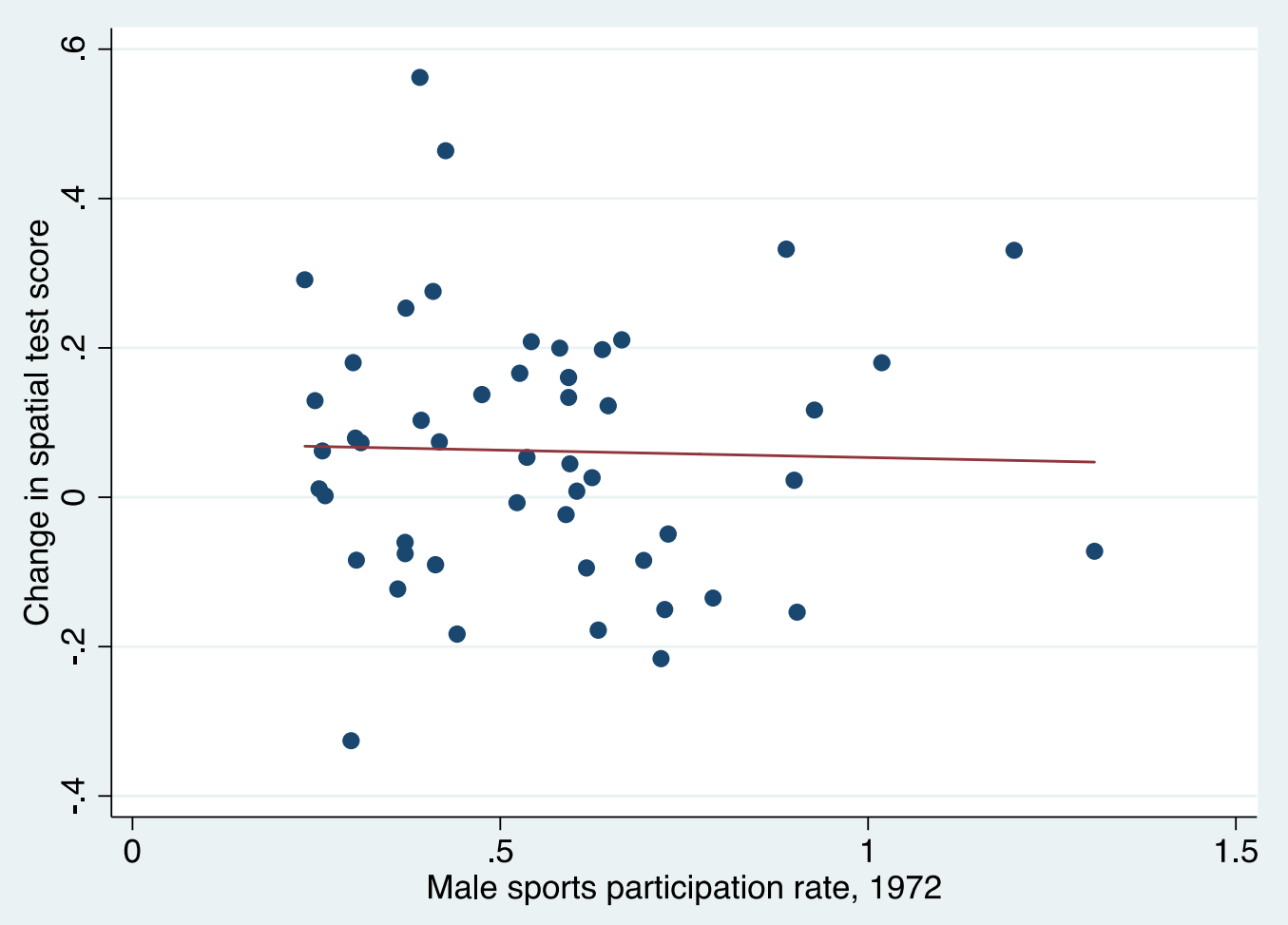

Notes: Authors' calculations from Project Talent, High School and Beyond, NFHS and NCES data. Each point represents the average change in females' performance on a test of visualization in three dimensions (standardized by year, across both men and women) for a given state, plotted against the male sports participation rate in 1972 . (Note that the total sports participation rate can be greater than one, because individuals may be counted in more than one sport.) 
Table 1: Gender differences in two dimensional and three dimensional spatial tests by grade: Project Talent (1960)

\begin{tabular}{lcccc}
\hline Grade & $\mathrm{N}$ & Two dimensional & $\mathrm{N}$ & Three Dimensional \\
\hline 9 & 100,501 & $-0.357^{* * *}$ & 100,369 & $-0.275^{* * *}$ \\
& & $(0.007)$ & & $(0.007)$ \\
10 & 96,295 & $-0.403^{* * *}$ & 96,298 & $-0.343^{* * *}$ \\
& & $(0.007)$ & & $(0.007)$ \\
11 & 89,505 & $-0.445^{* * *}$ & 89,485 & $-0.381^{* * *}$ \\
& & $(0.007)$ & & $(0.007)$ \\
12 & 77,179 & $-0.462^{* * *}$ & 77,135 & $-0.415^{* * *}$ \\
& & $(0.007)$ & & $(0.008)$ \\
\hline
\end{tabular}

Notes: Authors calculations from the Project Talent Base Year Data 1960. The reported statistics are from a regression of the standardized test score in 2D or 3D spatial ability on a female dummy variable and single month of age dummies. Robust standard errors in parentheses. *, ** and *** indicate statistical significance at the 10, 5 and 1 percent levels respectively.

Table 2: Gender differences in two dimensional and three dimensional spatial tests by age: Project Talent (1960)

\begin{tabular}{lcccc}
\hline Age & $\mathrm{N}$ & Two dimensional & $\mathrm{N}$ & Three Dimensional \\
\hline 12 & 238 & $-0.336^{* *}$ & 238 & $-0.375^{* * *}$ \\
& & $(0.133)$ & & $(0.132)$ \\
13 & 3,908 & $-0.317^{* * *}$ & 3,906 & $-0.233^{* * *}$ \\
& & $(0.035)$ & & $(0.035)$ \\
14 & 62,299 & $-0.343^{* * *}$ & 62,219 & $-0.265^{* * *}$ \\
& & $(0.008)$ & & $(0.009)$ \\
15 & 91,783 & $-0.368^{* * *}$ & 91,746 & $-0.305^{* * *}$ \\
& & $(0.007)$ & & $0.007)$ \\
16 & 94,774 & $-0.419^{* * *}$ & 94,773 & $-0.348^{* * *}$ \\
& & $(0.007)$ & & $0.007)$ \\
17 & 84,772 & $-0.449^{* * *}$ & 84,667 & $-0.392^{* * *}$ \\
& & $(0.007)$ & & $0.007)$ \\
18 & 22,493 & $-0.448^{* * *}$ & 22,493 & $-0.389^{* * *}$ \\
& & $(0.014)$ & & $0.014)$ \\
& & $-0.484^{* * *}$ & 3265 & $-0.448^{* * *}$ \\
& 3263 & $(0.037)$ & & $0.037)$ \\
\hline
\end{tabular}

Notes: Authors calculations from the Project Talent Base Year Data 1960. The reported statistics are from a regression of the standardized test score in 2D or 3D spatial ability on a female dummy variable and single grade of test dummies. Robust standard errors in parentheses. ${ }^{*}, * *$ and $* * *$ indicate statistical significance at the 10,5 and 1 percent levels respectively. 
Table 3: OLS estimates of the relationship between sports participation and the spatial content of occupational choice

\begin{tabular}{lcccc}
\hline & \multicolumn{2}{c}{ Aptitude - spatial } & \multicolumn{2}{c}{ Depth perception } \\
\hline Sports participation & $0.110^{* * *}$ & $0.213^{* * *}$ & $0.138^{* *}$ & $0.162^{* * *}$ \\
& $(0.034)$ & $(0.039)$ & $(0.060)$ & $\mathrm{X}$ \\
& & $\mathrm{X}$ & $\mathrm{X}$ & $\mathrm{X}$ \\
Age/race/sex & $\mathrm{X}$ & $\mathrm{X}$ & \\
covariates & & $\mathrm{X}$ & & \\
State fixed effects & & & $2,173,133$ & $2,173,133$ \\
& & $2,173,133$ & 0.166 & 0.172 \\
$\mathrm{~N}$ & $2,173,133$ & 0.109 & & \\
$\mathrm{R}^{\wedge} 2$ & 0.108 & &
\end{tabular}

Notes: The reported coefficients in this table are derived from a regression of the indicated job skill measure on the sports participation rate for a respondent's sex, state and cohort (using the 1972 participation rate for the 1980 respondents, and the 1978 participation rate for the year 2000 respondents.) The sample is the set of all employed men and women aged 25-34, from the 1980 and 2000 public use Census samples. Controls include an indicator for the year 2000, an indicator for female, 9 indicators for age and 4 indicators for race, as well as state fixed effects where indicated. The regression is weighted using person-level weights, and standard errors (shown in parentheses) are clustered at the state by cohort by sex level. *, ** and *** indicate statistical significance at the 10, 5 and 1 percent levels respectively. 
Table 4: Estimates of the impact of female sports participation on the spatial content of occupational choice

\begin{tabular}{|c|c|c|}
\hline & \multicolumn{2}{|c|}{ Dependent Variable } \\
\hline & \multicolumn{2}{|c|}{ Female participation rate } \\
\hline \multicolumn{3}{|l|}{ First Stage } \\
\hline Post $\mathrm{x}$ male participation, 1972 & \multicolumn{2}{|c|}{$\begin{array}{l}0.509^{* * *} \\
(0.057)\end{array}$} \\
\hline $\begin{array}{l}\text { First-stage F-statistic } \\
\mathrm{N}\end{array}$ & \multicolumn{2}{|c|}{$\begin{array}{c}80.1 \\
988,890\end{array}$} \\
\hline & Aptitude - spatial & Depth perception \\
\hline \multicolumn{3}{|l|}{ Reduced form } \\
\hline $\begin{array}{l}\text { Post } \mathrm{x} \text { male participation, } \\
1972\end{array}$ & $\begin{array}{l}-0.003 \\
(0.008)\end{array}$ & $\begin{array}{l}-0.008 \\
(0.018)\end{array}$ \\
\hline \multicolumn{3}{|l|}{ Instrumental Variables } \\
\hline Female participation rate & $\begin{array}{l}-0.006 \\
(0.015)\end{array}$ & $\begin{array}{l}-0.017 \\
(0.035)\end{array}$ \\
\hline State fixed effects & $\mathrm{X}$ & $\mathrm{X}$ \\
\hline Age/race controls & $\mathrm{X}$ & $\mathrm{X}$ \\
\hline $\mathrm{N}$ & 988,890 & 988,890 \\
\hline
\end{tabular}

Notes: First Stage - the estimated coefficient is from a regression of the female sports participation rate for the state and cohort to which an individual respondent belongs (with participation measured in 1972 for the 1980 sample, and 1978 for the 2000 sample) on "post" (an indicator for the year 2000 sample) and "post" interacted with the male sports participation rate in a respondents' state in 1972. Reduced form - the coefficients shown are derived from regressions of the indicated skill measure on "post" (an indicator for the year 2000 sample) and "post" interacted with the male sports participation rate in a respondents' state in 1972. Instrumental variables - the coefficients are derived from IV regressions of the indicated skill measure on the female sports participation rate for the state and cohort to which an individual respondent belongs (with participation measured in 1972 for the 1980 sample, and 1978 for the 2000 sample.) The female sports participation rate is instrumented with "post" interacted with the male sports participation rate in a respondents' state in 1972. All panels - the sample for all regressions is the set of women aged 25-34 who are employed in the civilian labor force, from the 1980 and 2000 public use Census samples. Controls include 9 indicators for age and 4 indicators for race, as well as state fixed effects. The regression is weighted using person-level weights, and standard errors (shown in parentheses) are clustered at the state by cohort by sex level. *, ** and *** indicate statistical significance at the 10, 5 and 1 percent levels respectively. 
Table 5: Estimates of the impact of female sports participation on a test of 3D spatial ability

\begin{tabular}{lc}
\hline \multicolumn{2}{l}{ Three dimension spatial skills } \\
\hline Reduced form & \\
\hline Post x male participation, & -0.053 \\
1972 & $(0.071)$ \\
\hline Instrumental Variables & \\
\hline Female participation rate & -0.104 \\
& $(0.136)$ \\
\hline State fixed effects & $\mathrm{X}$ \\
Age/race controls & $\mathrm{X}$ \\
$\mathrm{N}$ & 30,573 \\
\hline
\end{tabular}

Notes: Reduced form - the coefficients shown are derived from regressions of the visualization test score on "post" (an indicator for the year 19800 sample) and "post" interacted with the male sports participation rate in a respondents' state in 1972. Instrumental variables - the coefficients are derived from IV regressions of the visualization test score on the female sports participation rate for the state and cohort to which an individual respondent belongs (with participation measured in 1972 for the 1960 sample, and 1980 for the 2000 sample.) The female sports participation rate is instrumented with "post" interacted with the male sports participation rate in a respondents' state in 1972. Both panels - the sample for all regressions is the set of women aged 16-19 in the Project Talent (1960) and High School and Beyond (1980) datasets. Controls include 3 indicators for age and 2 indicators for race, as well as state fixed effects. The regression is weighted using person-level weights, and standard errors (shown in parentheses) are clustered at the state by cohort by sex level. *, ** and *** indicate statistical significance at the 10, 5 and 1 percent levels respectively. 
Table 6: Robustness tests for the relationship between Pre Title IX male high school sports participation and the spatial content of occupational choice.

\begin{tabular}{lcc}
\hline & \multicolumn{2}{c}{ Dependent Variable } \\
\hline Placebo reduced form regressions & Aptitude - spatial & Depth perception \\
\hline Post x male participation, & & $0.036^{*}$ \\
1972 & 0.018 & $(0.021)$ \\
& & $\mathrm{X}$ \\
State fixed effects & $\mathrm{X}$ & $\mathrm{X}$ \\
Age/race controls & $\mathrm{X}$ & $1970 / 1980$ \\
Years & $1970 / 1980$ & \\
$\mathrm{~N}$ & 551,318 & 551,318 \\
\hline Difference-in-differences reduced form regressions & 0.022 \\
\hline Female x post x male & 0.015 & $(0.089)$ \\
participation, 1972 & $0.065)$ & $\mathrm{X}$ \\
State fixed effects & $\mathrm{X}$ & $\mathrm{X}$ \\
Age/race controls & $\mathrm{X}$ & $2,173,133$ \\
$\mathrm{~N}$ & & 0.172 \\
$\mathrm{R} \wedge 2$ & $2,173,133$ & \\
\hline
\end{tabular}

Notes: Placebo reduced form - the estimates in this panel are derived from regressions of the indicated skill measure on "post" (an indicator for the year 1980 sample, "post" interacted with the male sports participation rate in a respondents' state in 1972. The sample for the regressions is the set of women aged 25-34 who are employed in the civilian labor force, from the 1970 and 1980 Census samples. Difference-in-differences reduced form - the estimates in this panel are from regressions of the indicated skill measure on an indicator for female interacted with "post" (an indicator for the year 1980 sample) and with the male sports participation rate in a respondents' state in 1972, as well as all one- and two-way interactions of these variables. The sample is the set of men and women aged 25-34 who are employed in the civilian labor force, from the 1980 and 2000 Census samples. Both panels - controls include 9 indicators for age and 4 indicators for race, as well as state fixed effects. The regression is weighted using person-level weights, and standard errors (shown in parentheses) are clustered at the state by cohort by sex level. *, $* *$ and $* * *$ indicate statistical significance at the 10,5 and 1 percent levels respectively. 
Table 7: Pre/Post Title IX changes in female participation, by sport

\begin{tabular}{lccc}
\hline & Female participation, & Female participation, & Change, 1972-1978 \\
\hline Baseball & 1972 & 1978 & \\
Basketball & $0.1 \%$ & $2.6 \%$ & $2.4 \%$ \\
Bowling & $1.8 \%$ & $7.3 \%$ & $5.5 \%$ \\
Cross-country & $0.0 \%$ & $0.1 \%$ & $0.1 \%$ \\
Golf & $0.0 \%$ & $0.6 \%$ & $0.6 \%$ \\
Gymnastics & $0.0 \%$ & $0.3 \%$ & $0.3 \%$ \\
Hockey & $0.2 \%$ & $1.1 \%$ & $0.9 \%$ \\
Ski- downhill & $0.0 \%$ & $0.8 \%$ & $0.8 \%$ \\
Soccer & $0.0 \%$ & $0.1 \%$ & $0.1 \%$ \\
Swimming & $0.0 \%$ & $0.2 \%$ & $0.9 \%$ \\
Tennis & $0.2 \%$ & $1.2 \%$ & $1.7 \%$ \\
Track and Field & $0.4 \%$ & $2.1 \%$ & $6.3 \%$ \\
Volleyball & $0.5 \%$ & $6.7 \%$ & $4.2 \%$ \\
Other & $0.1 \%$ & $4.3 \%$ & $0.4 \%$ \\
\hline
\end{tabular}

Notes: This table shows the female sports participation rate by sport and year. Participation rates are calculated using data on sports participation by gender, provided by the National Federation of High Schools. The participation rates are calculated by dividing the number of participants in each sport by estimated high school enrolment by gender for each year, based on NCES data. (The NCES does not provide enrolment by gender; we assume a 50\% gender split.) The set of sports shown are those that had non-zero male enrolment in 1972, and non-zero female enrolment in 1978. 
Table 8: "First stage” estimates of the relationship between female participation in specific sports and Pre Title IX male high school sports participation

\begin{tabular}{|c|c|c|c|c|c|c|c|}
\hline \multicolumn{8}{|c|}{ Female participation } \\
\hline \multirow{3}{*}{$\begin{array}{l}\text { Post x male } \\
\text { sports } \\
\text { participation, } \\
1972\end{array}$} & Baseball & Basketball & Bowling & Cross-country & Golf & Gymnastics & Hockey \\
\hline & $\begin{array}{l}-0.003 \\
(0.007)\end{array}$ & $\begin{array}{c}0.173 * * * \\
(0.019)\end{array}$ & $\begin{array}{l}-0.002 \\
(0.001)\end{array}$ & $\begin{array}{c}0.007^{*} \\
(0.004)\end{array}$ & $\begin{array}{c}0.013^{*} \\
(0.002)\end{array}$ & $\begin{array}{c}0.017^{* * *} \\
(0.005)\end{array}$ & $\begin{array}{c}-0.002 \\
(0.006)\end{array}$ \\
\hline & Skiing & Soccer & Swimming & Tennis & Track & Volleyball & Other \\
\hline $\begin{array}{l}\text { Post x male } \\
\text { sports } \\
\text { participation, } \\
1972\end{array}$ & $\begin{array}{c}0.001 \\
(0.002)\end{array}$ & $\begin{array}{l}-0.004 \\
(0.004)\end{array}$ & $\begin{array}{l}0.008^{* *} \\
(0.004)\end{array}$ & $\begin{array}{l}0.017^{* *} \\
(0.008)\end{array}$ & $\begin{array}{c}0.169^{* * *} \\
(0.037)\end{array}$ & $\begin{array}{c}0.117^{* * *} \\
(0.018)\end{array}$ & $\begin{array}{l}-0.003 \\
(0.002)\end{array}$ \\
\hline
\end{tabular}

Notes: The coefficients in this table are derived from regressions of the female participation rate in the indicated sport for the state and cohort to which an individual respondent belongs (with participation measured in 1972 for the 1980 sample, and 1978 for the 2000 sample) on "post" (an indicator for the year 2000 sample) and "post" interacted with the male sports participation rate in a respondents' state in 1972. The sample is the set of women aged 25-34 who are

employed in the civilian labor force, from the 1980 and 2000 public use Census samples. Controls include 9 indicators for age and 4 indicators for race, as well as state fixed effects. The regression is weighted using person-level weights, and standard errors (shown in parentheses) are clustered at the state by cohort by sex level. *, ** and *** indicate statistical significance at the 10, 5 and 1 percent levels respectively. 
Table 9: Estimates of the relationship between an analytic ranking of female high school sports participation and Pre Title IX male high school sports participation

\begin{tabular}{|c|c|c|}
\hline & \multicolumn{2}{|c|}{ Dependent Variable } \\
\hline & \multicolumn{2}{|c|}{ Female "analytic" ranking } \\
\hline First Stage & & \\
\hline Post x male participation, 1972 & \multicolumn{2}{|c|}{$\begin{array}{c}3.033^{* * *} \\
(0.310)\end{array}$} \\
\hline $\begin{array}{l}\text { First-stage F-statistic } \\
\mathrm{N}\end{array}$ & \multicolumn{2}{|c|}{94.8} \\
\hline & Aptitude - spatial & Depth perception \\
\hline \multicolumn{3}{|l|}{ Instrumental Variables } \\
\hline Female "analytic" ranking & $\begin{array}{c}-0.001 \\
(0.003)\end{array}$ & $\begin{array}{l}-0.004 \\
(0.008)\end{array}$ \\
\hline State fixed effects & $\mathrm{X}$ & $\mathrm{X}$ \\
\hline Age/race controls & $\mathrm{X}$ & $\mathrm{X}$ \\
\hline $\mathrm{N}$ & 988,890 & 988,890 \\
\hline
\end{tabular}

Notes: First stage - the estimates are derived from regressions of the female ranking in the "analytic" skill for high school sports, measured at the state by cohort level (with participation measured in 1972 for the 1980 sample, and 1978 for the 2000 sample) on "post" (an indicator for the year 1980 sample, and "post" interacted with the 1972 male sports participation rate in a respondents' state in 1972. Instrumental variables - the estimates in this panel are from IV regressions of the indicated skill measure on the female ranking in the "analytic" skill for high school sports, measured at the state by cohort level (with participation measured in 1972 for the 1980 sample, and 1978 for the 2000 sample). Both panels - the sample is the set of women aged 25-34 who are employed in the civilian labor force, from the 1980 and 2000 public use Census samples. Controls include 9 indicators for age and 4 indicators for race, as well as state fixed effects. The regression is weighted using person-level weights, and standard errors (shown in parentheses) are clustered at the state by cohort by sex level. *, ** and *** indicate statistical significance at the 10, 5 and 1 percent levels respectively 
Table 10: Principal-components analysis of job skill requirements

\begin{tabular}{|c|c|c|c|c|c|}
\hline & Component 1 & Component 2 & Component 3 & Component 4 & Component 5 \\
\hline \multicolumn{6}{|c|}{ Principal component analysis } \\
\hline Spatial aptitude & 0.191 & 0.744 & -0.046 & -0.087 & -0.633 \\
\hline Depth perception & 0.530 & 0.262 & 0.172 & 0.701 & 0.359 \\
\hline GED - reasoning & -0.371 & 0.608 & 0.055 & -0.287 & 0.638 \\
\hline $\begin{array}{l}\text { Temperament - } \\
\text { dealing with } \\
\text { people }\end{array}$ & -0.519 & 0.016 & 0.756 & 0.322 & -0.237 \\
\hline Physical strength & 0.525 & -0.090 & 0.628 & -0.561 & 0.084 \\
\hline Eigenvalue & 2.508 & 1.515 & 0.494 & 0.316 & 0.166 \\
\hline $\begin{array}{l}\text { Proportion of } \\
\text { variance explained }\end{array}$ & 0.502 & 0.303 & 0.099 & 0.063 & 0.033 \\
\hline $\mathrm{N}$ & 489 & 489 & 489 & 489 & 489 \\
\hline \multicolumn{6}{|l|}{ Reduced form } \\
\hline $\begin{array}{l}\text { Post } x \text { male sports } \\
\text { participation, } \\
1972\end{array}$ & $\begin{array}{l}-0.021 \\
(0.019)\end{array}$ & $\begin{array}{c}0.009 \\
(0.012)\end{array}$ & $\begin{array}{c}-0.084^{* * *} \\
(0.022)\end{array}$ & $\begin{array}{c}0.031 \\
(0.027)\end{array}$ & $\begin{array}{c}0.022 \\
(0.022)\end{array}$ \\
\hline Age/race controls & $\mathrm{X}$ & $\mathrm{X}$ & $\mathrm{X}$ & $\mathrm{X}$ & $\mathrm{X}$ \\
\hline State fixed effects & $\mathrm{X}$ & $\mathrm{X}$ & $\mathrm{X}$ & $\mathrm{X}$ & $\mathrm{X}$ \\
\hline $\mathrm{N}$ & 988,890 & 988,980 & 988,890 & 988,890 & 988,890 \\
\hline
\end{tabular}

Notes: Principal component analysis - the results in this panel are from a principal components analysis of five DOT job attributes: spatial aptitude, depth perception, GED - reasoning, temperament - dealing with people, and physical strength. Each attribute is normalized to have a mean of zero and standard deviation of 1 (across occupations) prior to the analysis. The coefficients in this panel represent the weightings on each variable in constructing the components. Positive weightings indicate that the component is positively correlated with the indicated skill, with larger values indicating a stronger relationship. Reduced form - the estimates in this panel are derived from regressions of the indicated principal component (weightings shown in Table 12) on "post" (an indicator for the year 2000 sample) and "post" interacted with the male sports participation rate in a respondents' state in 1972 . The sample is the set of women aged 25-34 who are employed in the civilian labor force, from the 1980 and 2000 Census samples. Controls include 9 indicators for age and 4 indicators for race, as well as state fixed effects. The regression is weighted using person-level weights, and standard errors (shown in parentheses) are clustered at the state by cohort by sex level. *, ** and *** indicate statistical significance at the 10,5 and 1 percent levels respectively. 